\title{
Diversity of Mold Associated with the Rotting of Peanut (Arachis Hypogaea) during Storage in Some Markets of Douala Cameroon
}

\author{
Mounbain Francis, Tchameni Séverin, Ntengna Yonkeu Fabrice, Jazet Dongmo Pierre \\ Micheal, Sameza Modeste Lambert and Tchoumbougnang François*
}

University of Douala, PO Box 24157, Douala, Cameroon

*Corresponding author

\section{A B S T R A C T}

\begin{tabular}{|c|c|}
\hline Keywords & \multirow{4}{*}{$\begin{array}{l}\text { During storage, peanut seeds face many problems including deterioration that creates } \\
\text { favorable conditions for mold growth and mycotoxin production. This study describes the } \\
\text { diversity of molds responsible for groundnut rot during commercialized in the city markets } \\
\text { of Douala-Cameroon. Peanut samples were collected in a ten markets in the city of } \\
\text { Douala. It has been noted that the postharvest fungal flora of groundnuts in the city of } \\
\text { Douala is composed of various genre of molds. Many fungal species have been isolated } \\
\text { and identified on peanut seeds commercialized in the study markets of the city of Douala. } \\
\text { A total of six thousand fungal isolates (6000) were obtained in post-harvest culture. The } \\
\text { main species are: Aspergillus flavus, Aspergillus niger, Fusarium oxysparum, Fusarium } \\
\text { solani, Fusarium vinale, Penicillium, Mucor, Rhizopus stonifer and Rhizoctonia solani. } \\
\text { Aspergillus is the most common genus (52\%), of all samples whatever the geographic } \\
\text { origin. All fungal groups are present in all markets of the city of Douala, and only differ in } \\
\text { proportion. }\end{array}$} \\
\hline $\begin{array}{l}\text { Pathogens, } \\
\text { Aspergillus, } \\
\text { Fusarium, } \\
\text { Penicillum, Mucor, } \\
\text { Rhizopus stonifer } \\
\text { and Rhizoctonia } \\
\text { solani }\end{array}$ & \\
\hline Article Info & \\
\hline & \\
\hline
\end{tabular}

\section{Introduction}

In Cameroon, agriculture contributes for about $22.9 \%$ of gross domestic product and represents the first employer with $62 \%$ of the active population Anonymous (2015). It is based on the growing cereals, starchy plants and legumes. As most of seed legumes, groundnuts occupy a place of choice in human nutrition Kouadio (2007). These seeds contain about $45-50 \%$ lipids, $25-30 \%$ protein, $12 \%$ carbohydrates, $3 \%$ fiber, water, minerals and vitamins Annerose (1990).
In Cameroon, groundnuts rank second after cotton in terms of economic profitability and this crop is used both as a cash crop and as a food or subsistence crop Magrin (2003).

Despite its nutritional, economic and positive effects, the different peanut varieties are the preferred substrate for molds, especially the genus Aspergillus Schmale et al., (2005). These attacks do not only affect the yield and nutritional value during storage, but also human health. Research studies in West Africa has referred to the attack and loss of stocks of cereals and legumes by insects and 
mycotoxins, which in the tropics are responsible for losses of up to 30\% Philogène et al., (1989), Ratnadass et al., (1989), Ashamo (2006) Tagne et al., (2003). However, in Cameroon, no work has been done to our knowledge on the diversity of molds that attack peanuts sold in the markets of the city of Douala.

Therefore, the objective of this study was to describe the diversity of molds responsible for groundnut rot during commercialized storage in the city markets of Douala-Cameroon. More specifically, to make a survey of varieties and mode of peanuts contamination in the study markets of Douala; to characterize (morphological and microscopic) the molds responsible for the rot of the different varieties of peanuts (Arachis hypogaea) sold in the city of Douala.

\section{Materials and Methods}

A survey form was established to collect informations on the sold varieties groundnuts, the conditions and their mode of storage. From the infected peanut seeds used in this study, mold that attack these foodstuffs where isolated and identified.

\section{Peanut sampling}

We sampled in ten major markets (Central, Dakar, Deido, Mabanda, Ndogpassi, New bell, Sandaga, Bonamoussadi, Bonassama, PK 14) of the city of Douala. The collections were made during the period from January to June 2016 for a sample of six thousand (6000) on 5 peanut varieties the most commercialized as show in Figure 1.

\section{Isolation and identification of molds}

Isolation of molds was done by direct contact on culture medium using Sabouraud Dextrose Agar (SDA) supplemented with chloramphenicol as antibacterial according to the method described by Foko and Sougnabe (1991). Infected peanut seeds were seeded aseptically in Petri dishes containing $10 \mathrm{~mL}$ of Sabouraud Dextrose Agar (SDA) supplemented with chloramphenicol. The culture was incubated during 3-5 days with cooler set at $25^{\circ} \mathrm{C}$ in order to observe the growth of the colonies of which numerous colonies of molds of various genus were observed and the percentage of contamination evaluated.

The operation was repeated many times to obtain pure culture of the isolate. Identity of the mold isolates was based on macroscopic and microscopic criteria as described by Jinyoung Lim et al., (2002), Agrios (2004) and Sameza et al., (2014).

\section{Results and Discussion}

The survey of varieties and peanut contamination in the study markets of Douala city revealed that five(5) varieties of peanut exist, three (3) are abundant in the city with a frequency of $47 \%$. The most widely consumed and commercialized varieties are Garoua (40\%), Makmak (37\%) and Yaounde (20\%) (Figure 2A). The most common pathogens that attack groundnut are molds (52\%), weevils (19\%) and bruchids (17\%) (Figure 2B).

\section{Morphological and microscopic characteristics of the main fungal species isolated from peanuts sold in the city of Douala}

Many fungal species were isolated and identified on commercialized peanut seeds in the study markets of the city of Douala. The main species are: Aspergillus flavus, Aspergillus niger, Fusarium Spp, Penicillium sp and Rhizoctonia Sp. 


\section{Aspergillus flavus}

Aspergillus flavusin pure culture has shown that the granular colony is white the first two days and then takes on a yellow, yellow or brown green color; the reverse of the dish is colorless (Figure 3A). Microscopic examination of the culture showed that conidiophores are swollen at the top and have many conidial-bearing cells. Conidia are hyaline and arranged in long chains or individualized (Figure 4A).

\section{Aspergillus niger}

Macroscopic examination of A. niger shows between the 2 nd day a first white thallus then takes towards the 4th day of culture a black shade surrounded with white (Figure 3B). The microscopic observation shows a fan structure with small, round and black spores (Figure 4B).

\section{Fusarium oxysparum}

In 4 day culture, the mycelium is cottony and white (Figure 3C). On microscope, two types of conidia are observed: microconidia, short and generally abundant, unicellular and macroconidia must slightly curved (Figure 4C).

\section{Rhizoctonia solani}

Rhizotonia solani colonies are cottony with a greyish to black coloring and the coating of the dish dark black (Figure 3D). On microscope, the mycelium is partitioned and presents a slight constriction at the level of the septa; it's provided by with side forming a right angle (Figure 4D).

\section{Penicillium sp.}

Penicillium sp. isolate obtained in young culture have a compact thallus, green surrounded by a white part but that become dark and powdery while getting old (Figure 3E). At the microscopic level, the conidiophores are more or less erect, partitioned, with a series of branches that gives a characteristic structure in the form of brush producing long chains of conidia (Figure 4E).

\section{Rhizopus stolonifer}

Rhizopus stolonifer gives very invasive colonies on the surface of the medium. Morphologically, it presents a white thallus, filamentous and aerial (Figure 3F). At the microscopic level, many spores called sporangiospore are enclosed in sporangia (Figure 4F).

\section{Mucorsp.}

Mucor Sp. colonies are generally downy, invasive and greyish white to yellowish in color. Conidiophores are generally straight, entangled each in the other (Figure 3G). At their extremities, they give birth to a sporangium containing numerous conidia. Conidia are spherical, smooth and variable sizes (Figure 4G).

\section{Fusarium nivale}

Fusarium nivale colonies consist of a sparse mycelium, very tenuous, first white then turning yellow and finally brown (Figure $3 \mathrm{H}$ ). Microscopically, there are no microconidia and the macroconidia are short, thick, hyalin, uniformly curved, one side being straight and the other curved. Conidia generally have $3-4$ spetas (Figure 4H).

\section{Distribution of isolated molds of peanut seeds sold in study markets}

Figure 5 shows the diversity of isolated molds of different peanut samples collected in the 
city of Douala. Several postharvest fungal isolates were grown in culture of which the most common genus are Aspergillus (52\%), Fusarium (21\%) and Penicillium (15\%).

\section{Geographical distribution of fungal genus}

The distribution of the main type's genus of mold according to the main sampling sites is shown in Figure 6, from which all samples are found to be contaminated with mold and differ only in proportion. Thus in each of these markets, the most important genus is Aspergillus with the most important proportion to the Central market (68\%) compared to 58 and $57 \%$ for the Dakar and Sandaga markets respectively

\section{Distribution of fungal genus according to} the peanut varieties recorded in the city of Douala

The figure 7 shows the distribution of fungal genus according to the varieties of peanuts sold in the markets of the city of Douala. It is noted that the most contaminated varieties are Garoua, Makmak and Yaounde. These by the molds dominance of the genus Aspergillus, Fusarium and Penicillium (Figure 7).

Despite the healthy appearance of peanut seeds sold in the city of Douala, they have been found to be contaminated by various fungal genera. This contamination is due to the initial charge in spores. Tahani et al., (2008) which after incubation find the favorable medium for their germination and the formation of mycelia. This shows that reducing the water content of peanut seeds by drying before storage does not eliminate mold spores, but makes their development unfavorable. If the storage conditions are unfavorable, these molds are factors of bio deterioration affecting the quality of the seeds. Furthermore, groundnut, by its high lipid and protein content, is a suitable medium that provides to the mold the nutrients needed for growth (Kassemi, 2006). Under the action of enzymes, complex polymers such as starch are transformed into simple molecules used by mold. Tabuc (2007), which could explain the high fungal density detected.

The genus Aspergillus, Fusarium, Penicillium, Rhizoctonia, Rhizopus and Mucor represent the common mycoflora of all collected samples. Previous studies have shown that peanut seed storage molds in India included the genus Alternaria, Aspergillus, Cladosporium, Colletotrichum, Fusarium, Penicillium, Rhizoctonia, Stemphylium and Trichoderma. Sud et al., (2005). Alternaria, Aspergillus, Fusarium, Moniliella, Penicillium and Rhizopus genus were isolated from Algerian samples. Djabali (2012).

These results indicate that seed fungal contamination during storage may be related to hydrothermal conditions.(Wilson et al., 2002) because the affected regions are subjected to completely different climatic conditions which would influence the fungal distribution. However, we can notice that the common fungal genera to all these regions are Aspergillus, Fusarium and Penicillium, with a predominance for the genus Aspergillus and Penicillium. Botton et al., (1990) have indeed pointed out that during storage, a flora consisting of less cellulolytic and more osmophilic fungi are developing, which cause acidification of the substrate; these are mainly Aspergillus and Penicillium which are two genus that proliferate mainly during storage on substrates whose low humidity such as peanuts during storage and products with reduced water activity (Castegnaro and Pfohl Leszkowicz, 2002). 
Fig.1 Peanut sampling (A, B, C, D, E represent Garoua, Makmak, Village,Yaounde andBafia peanut respectively)

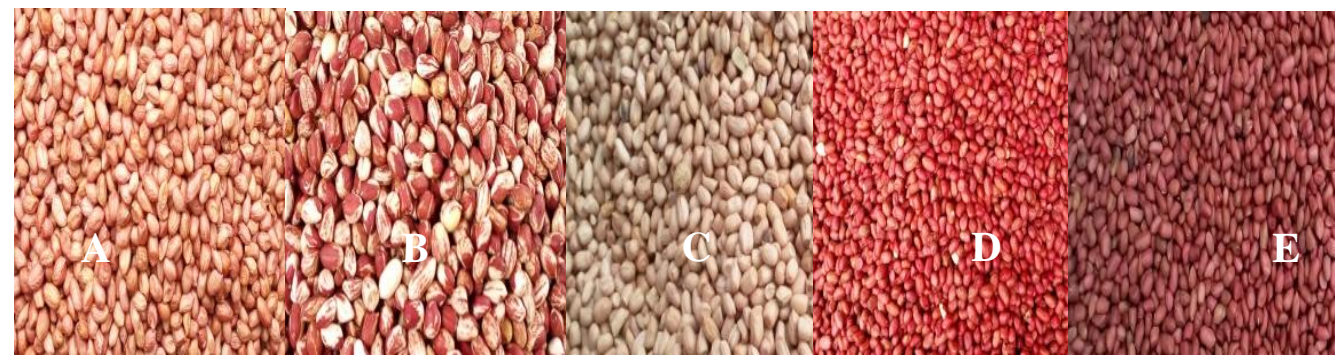

Fig.2 Varieties of peanut identified (A) and contaminant distribution during peanut storage (B)

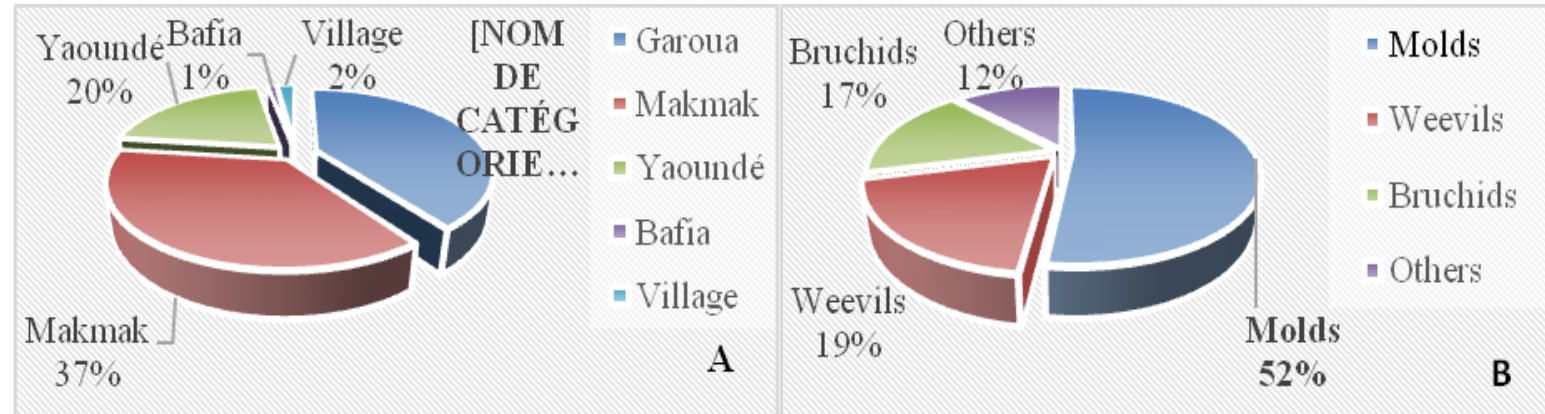

Fig.3 Aspect of different colonies of mold associated with the rotting of peanut seed (Arachishypogaea) during storage sold in the markets of Douala. A: Aspergillus flavus; B:

Aspergillus niger; C: Fusariumoxysparum; D: Rhizoctoniasolani;E: Penicilliumsp;F: Rhizopusstolonifer; G: Mucor Sp. and H: Fusariumnivale
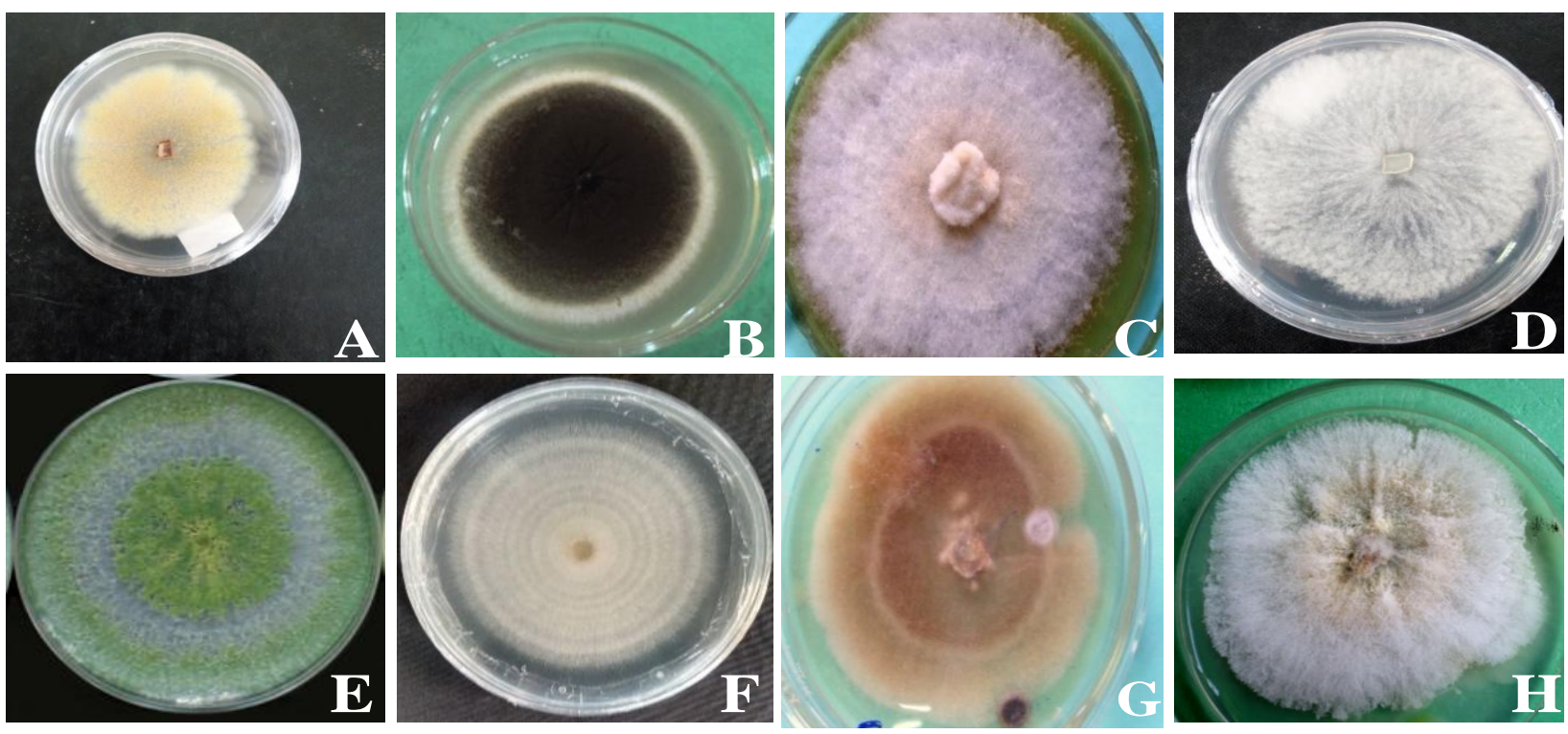
Fig.4 Microscopic observation of the main fungal species isolated from peanuts sold in Microconidia and macroconidia of Fusarium oxysparum; D: Mycelium of Rhizoctonia solani; E: Conidiophores producing long chains of conidia of Penicillium sp; F:Sporangiospore enclosed in sporangia of Rhizopus stolonifer; G: Conidiophores of Mucor Sp. and H:Microconidia and macroconidia of Fusarium nivale
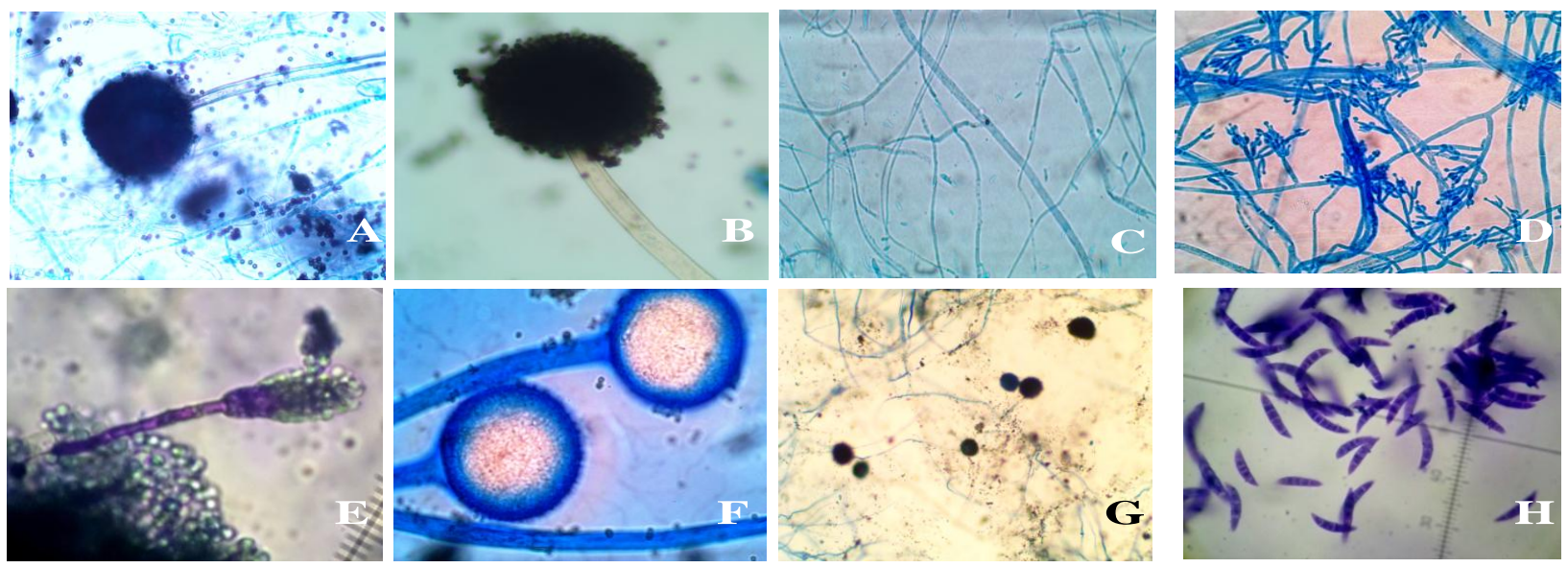

Fig.5 Diversity and proportion of fungal genus isolated from peanut samples in the city of Douala

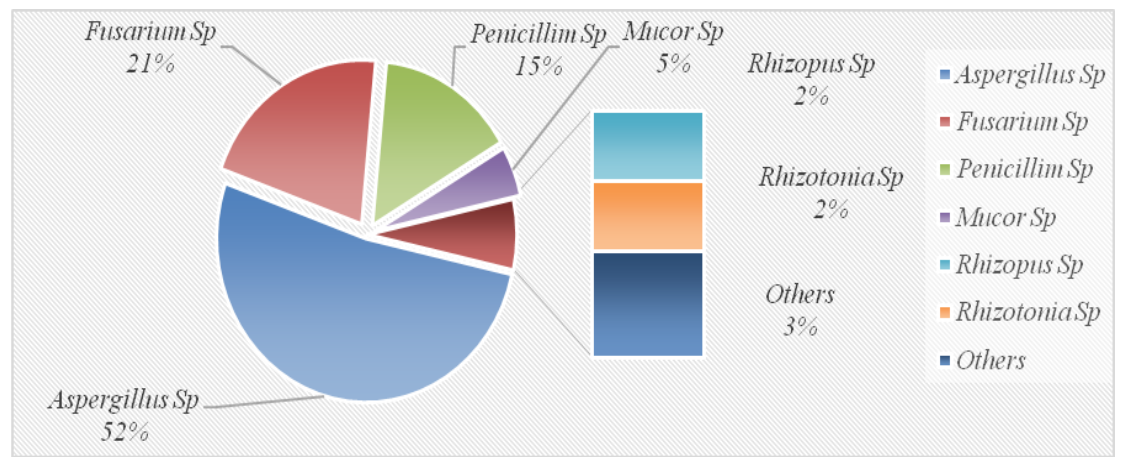

Fig.6 Diversity of different fungal genus according to markets

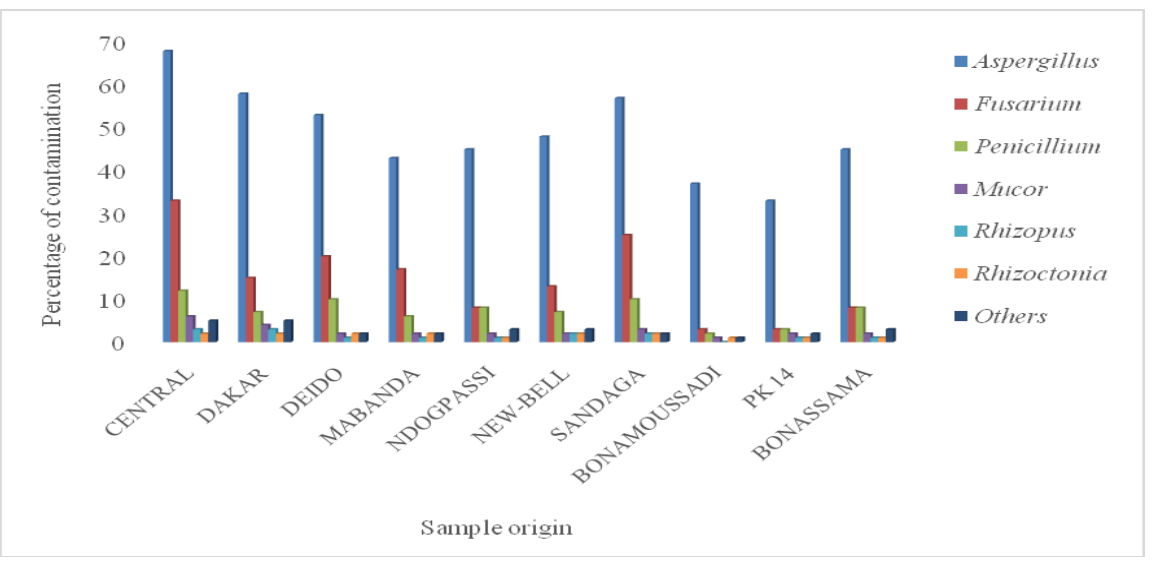


Fig.7 Distribution of fungal genus according to the peanut varieties recorded in the city of Douala

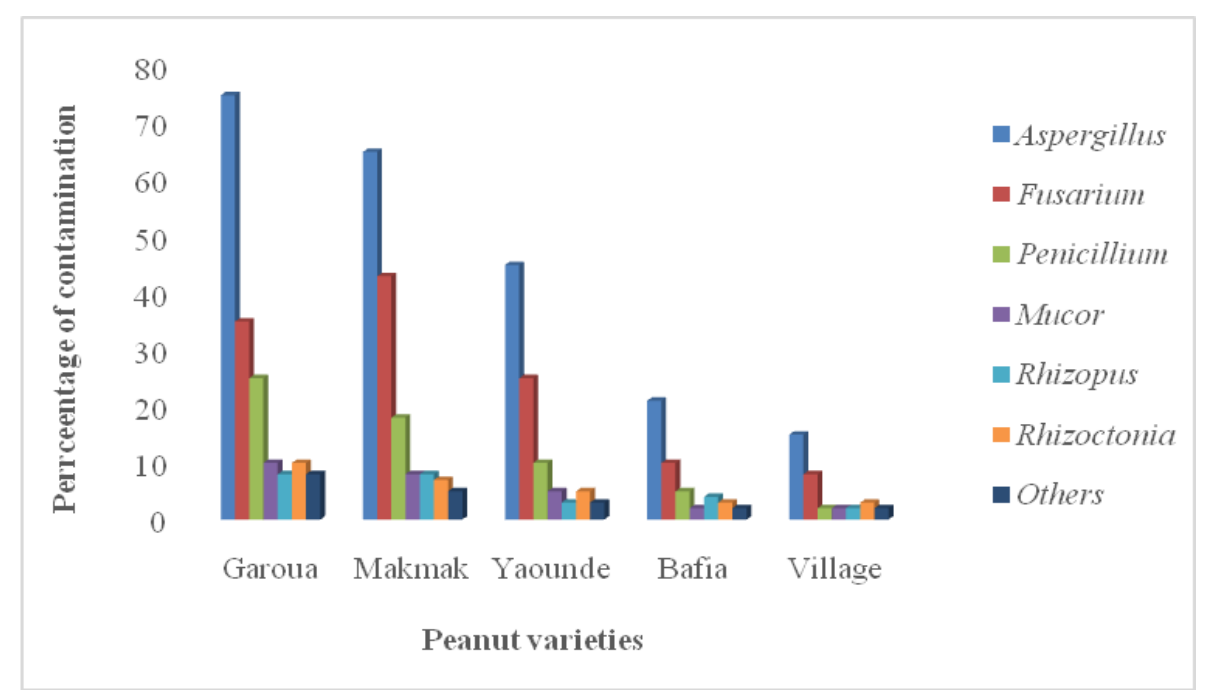

The highest contamination of peanut seeds by Aspergillus and Penicillium in all sampling sites indicates a potential danger because there is a possibility of a significant contamination of a flatoxin and ochratoxin; similarly, the significant representativity of the genus Fusarium is also an element of concern because of the many mycotoxins that can be produced. In this study, peanut samples collected from different sites in the city of Douala are contaminated with identical mold species with some ready exceptions, but at different rates. This could be explained by the fact that these different sampling sites are submitted to the same climatic conditions. A. Flavus followed by A. niger were the predominant fungal species in all peanut varieties from the sampling sites. These results show that the quality of the fungal species present on seeds in stock is related to the peanut variety and also to the initial spore load. Therefore, there is a positive correlation between fungal infestation and seed richness in these two elements (Abdel Massih, 2007).

In conclusion, findings from our study showed that there are several contaminations of the peanut samples. These could be due to the fact that postharvest fungal flora of peanuts in the city of Douala is composed of molds. However, further studies on molecular characterization to confirm their identification are needed.

\section{Acknowledgements}

The Authors thank the Biochemistry Laboratory of the Faculty of Sciences of the University of Douala (Cameroon) for the realization of this work.

\section{References}

Abdel Massih, M., 2007. Mold: identification, sources of contamination and control methods. Food technological pole :3.

Annerose, D.J.M., 1990. Research on the physiological mechanisms of adaptation to drought. Application to the case of peanut (Arachis hypogeae L.) grown in Senegal. Thesis. University of Paris VII., $282 \mathrm{p}$

Anonymous., (2015). Agricultural policies around the world: some examples. Agricultural context and international relations: Case of Cameroon. 
http://agriculture.gouv.fr/politiquesagricoles-fiches-pays

Ashamo, M.O., 2006. Relative susceptibility of some localand elite rice varieties to the rice weevil, Sitophilusoryzae L. (Coleoptera: Curculionidae). J. Food Agric. Environ., 4(1): 249-252.

Botton, B., Breton, A., Fevre M., Gauthier, S., Guy, P., Larpent, J.P., Reymond, P., Wild Boar, J.J., Vayssier Y., Calf P. 1990. Useful and harmful molds, Industrial importance, Ed. Masson, Paris. 512p.

Castegnaro, M., Pfolhl-Leszkowicz, A.2002. Mycotoxins: omnipresent contaminants in animal and human nutrition. Moll. \& Moll. (Eds). Food safety of the consumer. Lavoisier, Tec $\&$ doc. Lavoisier, Londres, Paris, New York.: 127-179.

Djabali, S., 2012. Effect of polyphenols on resistance to fungal infestation in dry bean grain. Memoir Presented for graduation from Magister in Food Science. Mentouri-Constantine University. 122Pp.

Foko, J., Sougnabe. 1991. Composition, infection sites and evolution of groundnut fungal spermoflora in the Mayo-kebbi basin (Tchad). Bioscience Proccess. 2:314 - 317.

Kassemi, N., 2006. Relationship between a phytophagous insect and its main host plant: case of the bean weevil (Acanthoscelides obtectus) (Coleoptera bruchidae). Magister thesis. University of Tlemcen, Algeria. $107 \mathrm{p}$.

Kouadio, A. L., 2007. Interuniversity in natural risk management: Forecast of national groundnut production in Senegal from the agro-meteorological model AMS and NDVI. ULGGembloux $54 \mathrm{p}$.

Margin, G., 2003. A subregional food crop: peanut. In: Atlas Agriculture and
Rural Development of Central African savannahs. CIRAD / PRASAC. P. 63 $-64$

Philogène, B.J. R, Armson, J.T. and Lambert, J.D.H. 1989.Factors contributing to the protection of maize against Sitophilus and Prostephanus attacks. Cereals in warm regions. Paris: AUPELF-UREF, John Libbey Eurotext, 47-56

Ratnadssa, A. and Sauphanor, B. 1989. Losses due to insects on cereals farmer's stocks in the coast of ivory. Cereals in hot regions. Paris: Aupelf Uref, John Libbey Eurotext. 141-150

Sameza, M.L., Bedine Boat, M.A., Tchameni, N.S., Nguemnang M.C.L., Jazet, D.P.M., Fekam, B.F., Menut, C.2014. Potential use of Eucalyptus globulus essential oil against Phytophthora colocaciae, the causal agent of taro leaf blight. Eur J Plant Phytopathol. 140:243-250.

Schmale, D.G., Arntsen, Q.A., Bergstrom, G.C., 2005. The forcible discharge distance of ascospores of Gibberella zeae. Canadian Journal of Plant Pathology. 27: 376 - 383.

Sud D., Sharma, O.P., Sharma, P.N. 2005. Seed mycoflora in kidney bean (Phaseolus vulgaris L.) in Himachal Pradesh. Seed Science Research. 33: 103-107.

Tabuc, C., 2007. Fungal flora of different substrates and optimal conditions of mycotoxin production. Thesis presented to obtain the title of Doctor of the National Polytechnic Institute of Toulouse and the University of Bucharest. 190p.

Tagne, A., Kongsdal, O., Ngoko, Z., The C. Mathur, SB. 2003.Fusarium pallidorosum in maize samples of three agro-ecological zones of Cameroon. Journal of Stored Product Research. 39: 367-374. 
Tahani, N., Elamrani, A. Serghini-Caid, H., Ouzouline, M., Khalid, A., 2008. Isolation and identification of mold strains reputed toxinogenic. Journal of Industrial Microbiology Sanitary and Environmental. 2: 81-91.
Z., 2002. Biology and ecology of mycotoxigenic Aspergillus species as related to economic and health concerns, $A d v$. Experiment and Medical Biology. 504: 3-17.

Wilson, D.M., Mubatanhema, W., Jurjevic,

\section{How to cite this article:}

Mounbain Francis, Tchameni Séverin, Ntengna Yonkeu Fabrice, Jazet Dongmo Pierre Micheal, Sameza Modeste Lambert and Tchoumbougnang François. 2019. Diversity of Mold Associated with the Rotting of Peanut (Arachis Hypogaea) during Storage in Some Markets of Douala Cameroon. Int.J.Curr.Microbiol.App.Sci. 8(04): 1406-1414. doi: https://doi.org/10.20546/ijcmas.2019.804.163 